ments of T7 DNA and determination of molecular weights by electrophoresis in neutral and alkaline gels. J. Mol. Biol. 110:119-146.

18.Myers, T.W. and D.H. Gelfand. 1991. Reverse transcription and DNA amplification by Thermus thermophilus DNA polymerase. Biochem. 30:7661-7666.

19.Myers, T.W. and C.L. Sigua. 1995. Amplification of RNA: high-temperature reverse transcription and DNA amplification with Thermus thermophilus DNA polymerase, p. 58-68. In M.A. Innis, D.H. Gelfand, and J.J. Sninsky (Eds.), PCR Strategies. Academic Press, New York

20.Wu, W., L.E. Henderson, T.D. Copeland, R.J. Gorelick, W.J. Bosche, A. Rein, and J.G. Levin. 1996. Human immunodeficiency virus type 1 nucleocapsid protein reduces reverse transcriptase pausing at a secondary structure near the murine leukemia virus polypurine tract. J. Virol. 70:7132-7142.

Address correspondence to Dr. Gary F. Gerard, Transgenomic, Inc., 11 Firstfield Road, Suite E, Gaithersburg, MD 20878, USA.e-mail: ggerard@transgenomic.com

Received 31 May 2002; accepted 9 July 2002.

Gary F. Gerard, Sarah Collins, and Michael D. Smith Invitrogen

Frederick, MD, USA

For reprints of this or any other article, contact Reprints@BioTechniques.com

\section{Cloning Method for Taxonomic Interpretation of T-RFLP Patterns}

\section{BioTechniques 33:990-992 (November 2002)}

Terminal RFLP (T-RFLP) is a recently introduced PCR-based tool for studying diversity among amplified DNA molecules with the same size (4). Terminal restriction fragment (TRF) patterns obtained using the T-RFLP technique are generated and analyzed in a procedure that combines PCR with a labeled primer, restriction digestion of the amplified DNA, and separation of fragments in an automated se- quencer. One of the most interesting applications of T-RFLP is its use for the description of genetic diversity within a bacterial community $(2,3,7)$. In this case, the PCR is performed using primers annealing to conserved sequences of $16 \mathrm{~S}$ rRNA gene, and the TRF pattern obtained represents a "picture" of the number of different $16 \mathrm{~S}$ rRNA genes present in the community (i.e., different operating taxonomic units). One of the main limits of this technique is the difficulty of obtaining taxonomic information of the organisms responsible for a particular TRF. To allow the interpretation of TRFs, an online tool has been developed called TAP (T-RFLP Analysis Program; Reference 5) that performs in silico PCR amplification and restriction of the $16 \mathrm{~S}$ rDNA sequences present in the Ribosomal Database (RDPII, Center for Microbial Ecology at Michigan State University, http://rdp.cme.msu.edu/ html/TAP-trflp.html\#program). However, database matching of TRF sizes is imprecise and may not produce species- or even genus-specific assignment (2), and results can be experimentally verified indirectly only after a long screening of a $16 \mathrm{~S}$ rDNA library.

Here we present a simple and fast method that allows for an empirical taxonomic interpretation of TRFs. This method would be particularly useful when a detailed taxonomic description of a bacterial community is needed. Figure 1 depicts the flow chart of the methodology. The method is based on the ligation of the TRFs with oligonucleotide adapters, subsequent PCR-amplification, cloning, and final sequencing of the single TRFs.

We used this technique to identify the bacterial groups represented in a TRF pattern obtained from soil DNA. DNA was extracted with the Fast Prep DNA Kit for Soil ${ }^{\mathrm{TM}}$ (BIO101, Qbiogene, Carlsbad, CA, USA) from $0.5 \mathrm{~g}$ fresh soil collected in a wood of cypress near Florence (Italy). The $16 \mathrm{~S}$ rDNA was amplified in a $50-\mu \mathrm{L}$ volume with $2 \mathrm{U}$ Taq DNA polymerase (Dynazyme II $^{\mathrm{TM}}$; Finnzyme, Espoo, Finland) using $27 \mathrm{f}$ primer labeled with TET $\left(4,7,2^{\prime}, 7^{\prime}\right.$ tetrachloro-6-carboxyfluorescein) and $1495 \mathrm{r}$ primer (6). The amplified products were purified with a QIAquick ${ }^{\mathrm{TM}}$ PCR purification kit (Qiagen, Valencia, CA, USA), and $600 \mathrm{ng}$ were digested with $20 \mathrm{U}$ MspI or HhaI (New England Biolabs, Beverly, MA, USA) for $3 \mathrm{~h}$ at $37^{\circ} \mathrm{C}$. The digested products $(200 \mathrm{ng})$ were resolved by capillary electrophoresis on an ABI 310 Genetic Analyzer $^{\mathrm{TM}}$ using TAMRA 500 as size standard for GenScan ${ }^{\mathrm{TM}}$ (all from Applied Biosystems, Foster City, CA, USA) analysis. The restricted products (200 ng) were ligated with 10 pmol complementary double-stranded adapter with 10 U T4 DNA ligase (New England Biolabs) for $10 \mathrm{~h}$ at $14^{\circ} \mathrm{C}$ in a $10-\mu \mathrm{L}$ volume. One microliter of the ligation reaction was PCR-amplified using $27 \mathrm{f}$

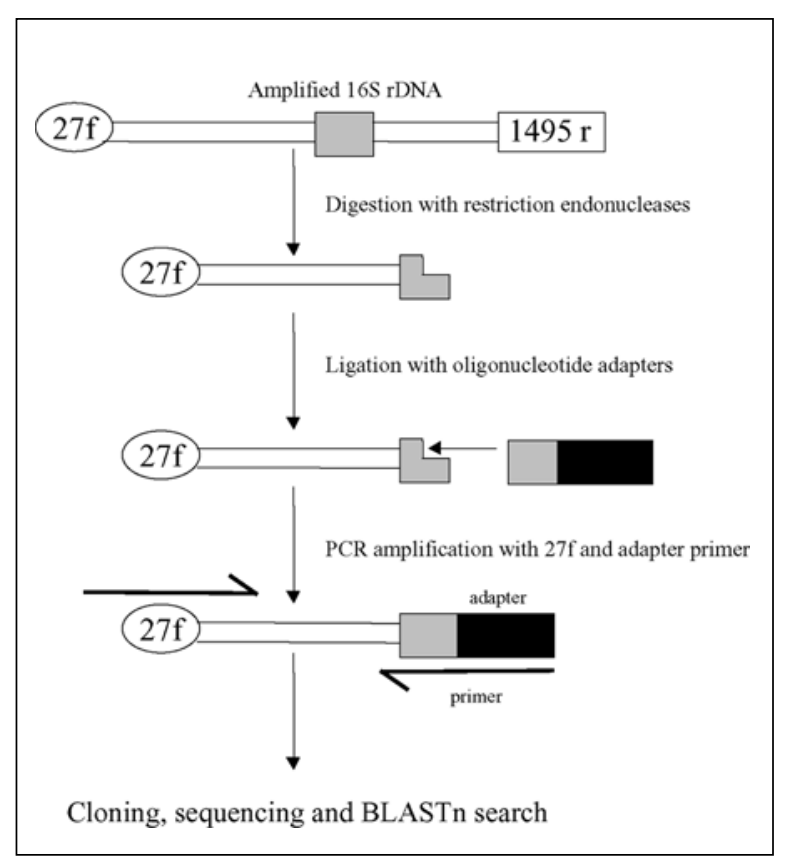

Figure 1. Schematic representation of the cloning system. The nucleotide sequences of the double-stranded adapters used are as follows. For MspI, 5'-CGCTCGTAGACTGCGTACC-3' and 3'-GAGCATCTGACGCATGGTTAA-5' . For HhaI, 5'-GAGCATCTGACGCATGGTTAA-3' and $3^{\prime}$-GCCTCGTAGACTGCGTACC-5'. The PCR amplification of the ligated products was performed using the following temperature profile in a Primus $96^{\mathrm{TM}}$ Thermal Cycler (MWG-AG-Biotech, Ebersberg, Germany): $2 \mathrm{~min}$ at $94^{\circ} \mathrm{C}$, followed by 35 cycles of $30 \mathrm{~s}$ at $94^{\circ} \mathrm{C}, 30 \mathrm{~s}$ at $55^{\circ} \mathrm{C}$, and $30 \mathrm{~s}$ at $72^{\circ} \mathrm{C}$. 
and pMspI (5'-GGTACGCAGTCTACGAGCGG-3') or pHhaI (5'-CCATGCGTCAGATGCTCCGC-3') reverse primers, which were designed on the sequence of the double-stranded adapter and on the half restriction site of $M s p \mathrm{I}$ and $H h a \mathrm{I}$, respectively. The amplified fragments were resolved on a $2 \%$ agarose gel, and the bands at molecular weights from 30 to $300 \mathrm{bp}$ were eluted from the gel (MinElute ${ }^{\mathrm{TM}} \mathrm{Gel}$ Extraction Kit; Qiagen) and cloned in the $\mathrm{pDrive}^{\mathrm{TM}}$ vector (Qiagen PCR Cloning Kit; Qiagen). This procedure allows for great reduction and faster screening of the clone library needed, when compared with cloning the original 16S rDNA products before digestion. A rapid screening for clones of appropriate size corresponding to specific TRF peaks was performed by PCR, using the standard M13 primer pair (M13forward primer labeled with TET), and the size of the cloned TRFs was verified by capillary electrophoresis of the amplified products in the ABI 310 Genetic Analyzer. All cloned and sequenced fragments were represented in the TRFLP profile. The most abundant fragments in the original T-RFLP were found to be predominant also in the library. However, a bias toward a higher content of fragments around $100 \mathrm{bp}$ was found, probably due to PCR amplification. Twelve selected clones (six for each of the two enzymes) were then sequenced using the BigDye ${ }^{\mathrm{TM}}$ Terminator (v.2) chemistry (Applied Biosystems). Sequences were used to perform a BLASTn search (1) on the GenBankEMBL-DDBJ database. All the obtained fragments were found to be significantly similar to sequences present in GenBank, with score and E-value varying from 44 and $1 \mathrm{e}-3$ for the smallest fragment ( $33 \mathrm{bp}$ ) to 321 and 1e-85 for larger fragments (202 bp). In general, the longer the fragment, the higher the score is. The taxonomic interpretation derived from BLAST matching was then compared with that obtained by using the TAP tool; in four cases out of the 12 analyzed (TRFs produced with $M s p I$ at 64, 202, 212, and 33 bp), TAP failed to show any matching, while the BLAST matching of the sequences found that those fragment were similar to $16 \mathrm{~S}$ rDNA bacterial sequences present in GenBank (with score and E-values varying from 46 and 1e-3 to 321 and 1e-85). In two cases, the BLAST matching of the sequenced TRF was different from the matching produced by TAP (TRFs produced with $M s p$ I at $174 \mathrm{bp}$ and with $H h a \mathrm{I}$ at $38 \mathrm{bp}$ ). In the remaining cases, the two procedures were well in agreement (TRFs produced with $M s p \mathrm{I}$ at 68 and $145 \mathrm{bp}$ and with $H h a \mathrm{I}$ at 82, 86, 89, and $95 \mathrm{bp}$ ). The reported results demonstrate that the direct cloning of TRFs could be a useful tool, complementary to TAP matching, for the taxonomic interpretation of TRFLP community profiles.

\section{REFERENCES}

1.Altschul, S.F., W. Gish, W. Miller, E.W. Myers, and D.J. Lipman. 1990. Basic local alignment search tool. J. Mol. Biol. 215:403410.

2.Kitts, C.L. 2001. Terminal restriction fragment patterns: a tool for comparing microbial communities and assessing community dynamics. Curr. Issues Intes. Microbiol. 2:17-25.

3.Liu, W.-T., T.L. Marsh, H. Cheng, and L.J., Forney. 1997. Characterization of microbial diversity by determining terminal restriction fragment length polymorphism of genes encoding 16 rRNA. Appl. Env. Microbiol. 63:4516-4522.

4.Marsh, T.L. 1999. Terminal restriction fragment length polymorphism (T-RFLP): an emerging method for characterizing diversity among homologous populations of amplification products. Curr. Op. Microbiol. 2:323-327.

5.Marsh, T.L., P. Saxman, J. Cole, and J. Tiedje. 2000. Terminal restriction fragment length polymorphism analysis program, a Web-based research tool for microbial community analysis. Appl. Env. Microbiol. 66:3616-3620.

6.Mengoni, A., R. Barzanti, C. Gonnelli, R. Gabbrielli, and M. Bazzicalupo. 2001. Characterization of nickel-resistant bacterial communities isolated from serpentine soil. Environ. Microbiol. 3:691-698.

7.Osborn, A.M., E.R.B. Moore, and K.N. Timmis. 2000. An evaluation of terminal-restriction fragment length polymorphism (TRFLP) analysis for the study of microbial community structure and dynamics. Environ. Microbiol. 2:39-50.

Address correspondence to Dr. Alessio Mengoni, Dipartimento di Biologia Animale e Genetica, Università di Firenze, via Romana 17, I-50125 Firenze, Italy. e-mail: alessiome@unifi.it

Received 10 June 2002; accepted 5 August 2002.

Alessio Mengoni, Eva Grassi, and Marco Bazzicalupo

Università di Firenze

Firenze, Italy

\section{Molecular Cloning Using the Interrupted Recogni- tion Sequence of $B p l I$ to Select for Recombinant Molecules}

BioTechniques 33:992-996 (November 2002)

The cloning of DNA fragments into a uniquely restricted target vector is a common procedure for constructing genomic DNA or cDNA libraries. The recovery of recombinant molecules is 